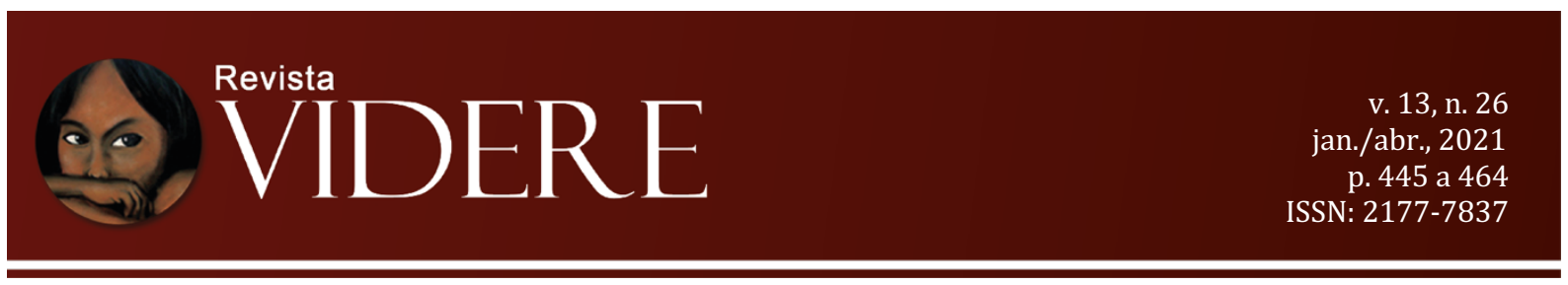

\title{
BEM VIVER E GÊNERO: APROXIMAÇÕES E REFLEXÕES DECOLONIAIS
}

\author{
GOOD LIVING AND GENDER: DECOLONIAL APPROACHES AND REFLECTIONS
}

BUEN VIVIR Y GÉNERO: APROXIMACIONES Y REFELXIONES DECOLONIALES

\author{
Cláudia Cinara Locateli \\ Mestre em Direito/UNOESC \\ Docente na Universidade do Oeste de Santa Catarina \\ claudia.locateli@unoesc.edu.br \\ OrcidID: https://orcid.org/0000-0002-5225-194X
}

Thaís Janaina Wenczenovicz

Pós-doutora em Educação/UNIOESTE

Docente na Universidade Estadual do Rio Grande do Sul/UERGS

Docente Titular no Programa de Pós-Graduação em Direito na Universidade do Oeste de Santa

Catarina/UNOESC

t.wencze@terra.com.br

OrcidID: http://orcid.org/0000-0001-9405-3995

Resumo: A alternativa andina do bem viver indica alcançar a sustentabilidade pelo equilíbrio da dimensão intersubjetiva, sociocultural e socioambiental como episteme do bem-estar. No desenvolvimento, as estruturas de poder que marcam a desigualdade de gênero geram privações, subalternizações e impedem alcançar a sustentabilidade. $O$ estudo investiga o bem viver como paradigma da sustentabilidade social em igualdade de gênero pela episteme do feminismo decolonial. Essa análise assenta-se no objetivo de refletir sobre a proposta do bem viver e as questões de gênero como condição essencial à sustentabilidade. Sabe-se que a proposta do bem viver visa fortalecer as relações humanas interculturais em conexão com o ambiente e sintoniza a necessidade de promover a superação de um determinismo biológico binário que articula as subjetividades e as interseccionalidades ampliando as desigualdades. Utiliza-se como procedimento metodológico o bibliográfico-investigativo. Nesse contexto, o bem viver permite avançar na conquista da equidade como direito humano e fundamental.

Palavras-chave: Bem Viver. Feminismo Decolonial. Gênero. Sustentabilidade Social.

Abstract: The andean alternative of the good life indicates achieving sustainability by balancing the intersubjective, sociocultural, and socio-environmental dimensions as the episteme of welfare. In development, power structures that mark gender inequality generate 
deprivations, subalternizations, and prevent achieving sustainability. The study investigates the good life as a paradigm of social sustainability in gender equality through the episteme of decolonial feminism. This analysis is based on the objective of reflecting on the proposal of the good life and gender issues as an essential condition for sustainability. It is known that the proposal of the good life aims to strengthen intercultural human relationships in connection with the environment and tunes the need to promote the overcoming of a binary biological determinism that articulates the subjectivities and intersectionalities amplifying inequalities. The bibliographical-investigative methodological procedure is used. In this context, the good life allows us to advance in the conquest of equity as a human and fundamental right.

Keywords: Good Living. Decolonial Feminism. Gender. Social Sustainability

Resumen: La alternativa andina del bien estar indica lograr la sostenibilidad equilibrando la dimensión intersubjetiva, sociocultural y socioambiental como un episteme de bien estar. En el desarrollo, las estructuras de poder que marcan la desigualdad de género generan privación, subalternización y evitan lograr la sostenibilidad. El estudio investiga el bien vivo como paradigma de la sostenibilidad social en la igualdad de género por el episteme del feminismo decolonial. Este análisis se basa en el objetivo de reflexionar sobre la propuesta de los bien vivos y las cuestiones de género como condición esencial para la sostenibilidad. Se sabe que la propuesta de una vida bien viva tiene como objetivo fortalecer las relaciones interculturales humanas en relación con el medio ambiente y en sintonía la necesidad de promover la superación de un determinismo biológico binario que articule subjetividades e interseccionalidades mediante la expansión de las desigualdades. El procedimiento bibliográfico-investigativo se utiliza como procedimiento metodológico. Sin embargo, el buen vivir permite avanzar em la consecución de la equidade como derecho humano y fundamental.

Palabras clave: Buen vivir. Feminismo Decolonial. Género. Sostenibilidad Social.

\section{Introdução}

O modo econômico capitalista tem sido alvo de críticas pela lógica que valoriza o produto interno bruto, a produção e o consumo, desprezando as potencialidades humanas e sua inserção com o meio ambiente e cultura. Esse modelo pauta-se na ideia de estado de bem-estar social que tem demonstrado insuficiência estrutural por manter a lógica ultraneoliberal, responsável pela generalizada exclusão social. No projeto econômico e político, a ausência de uma perspectiva da satisfação humana que não se reduza ao consumo e à exploração da natureza foram percebidas pela agenda política internacional. As reivindicações foram recepcionadas pelo Relatório Brundtland que atenta às múltiplas dimensões da sustentabilidade, apresenta propostas inseridas a um quadro mais amplo que se assemelha, em partes, às premissas do bem viver do projeto idealizado pelas teorias decoloniais latino-americanas. 
Para essa reflexão utiliza-se o conceito de bem viver como um conjunto de conhecimentos e saberes indígenas ancestrais (cosmovisão andina) que permite estabelecer uma relação harmoniosa com a natureza (Pachamama). O bem viver como um projeto político alternativo propõe adotar a filosofia da melhoria da qualidade de vida em dimensões intersubjetivas, socioculturais e socioambientais. O foco promove a ampliação das capacidades humanas inseridas na relação com a cultura e a natureza, o que gera liberdades e reduz privações, inclusive as derivadas das grades que aprisionam pela categoria binária do sexo, fortalecendo o acesso e a participação feminina na economia e na política. O bem viver alinhado ao contexto do feminismo decolonial reconhece a interculturalidade, sem dominação, respeita as diferenças sociais, culturais e econômicas, e promove a perspectiva da isonomia pela descontinuidade das relações de poder.

É neste cenário de exclusões, ampliado pela política econômica neoliberal, que emerge investigar se a proposta andina do bem viver constitui-se numa alternativa decolonial viável à sustentabilidade social pela superação das privações motivadas pela desigualdade de gênero. Para compreender o objetivo proposto, o estudo investiga o bem viver como paradigma da sustentabilidade social em igualdade de gênero pela episteme do feminismo decolonial. Desse modo, a pesquisa aborda, inicialmente, as definições da sustentabilidade social no projeto do bem viver, bem como as convergências epistêmicas com o desenvolvimento, a exemplo de liberdade e condição humana, para, na sequência, compreender o gênero nas políticas da sustentabilidade e, por fim, apresentar, pelo raciocínio indutivo, a proposta de alcançar uma igualdade de gênero, conectada ao bem viver, como uma proposta eficaz de sustentabilidade social.

A reflexão constitui um exercício que correlaciona as teorias do desenvolvimento sustentável e igualdade de gênero, com base em pesquisa bibliográfica, documental e pelo levantamento de dados, em abordagem exploratório-analítica. O suporte teórico ratifica a adoção dos preceitos do bem viver como proposta para efetivar a isonomia de gênero em harmonia com as premissas do feminismo de política decolonial, pela ruptura da dominação patriarcal e eurocêntrica, como condicionante à sustentabilidade.

\section{A sustentabilidade no bem viver}

O modelo capitalista, baseado na inclusão de um estado de bem-estar social, não se sustentou com a adoção da política neoliberal, gerou contradições que agravam a exclusão 
social. Aliado à lógica da globalização, o modelo impede racionalizar uma redução do crescimento econômico como forma necessária para valorizar a vida, o bem-estar humano, os recursos naturais e as manifestações interculturais. A proposta de uma concepção mais engajada da economia com a sustentabilidade pode confluir em possibilidades socioecológicas e interculturais à sociedade justa e igualitária. Essa racionalização não é nova, nem inédita, lançada na década de setenta, na Conferência de Estocolmo, com base no marco teórico do ecodesenvolvimento, incorporou-se à ideia da sustentabilidade.

Com a mesma toada, em 1987, o Relatório Brundtland, elaborado pela Comissão Mundial sobre o Meio Ambiente e Desenvolvimento, apresentou um conceito de desenvolvimento sustentável que o definiu como "O processo que satisfaz as necessidades presentes, sem comprometer a capacidade das gerações futuras de suprir suas próprias necessidades." (ONU, 1987). O referido relatório apresenta incompatibilidades entre o desenvolvimento e os padrões da lógica capitalista e neoliberal que supervalorizam o produto interno bruto, a produção e o consumo, revelando a necessidade de inter-relação entre as potencialidades humanas, a sua inserção na cultura e no meio ambiente.

Pelos termos propostos, a sustentabilidade deve ser considerada em sua natureza social, política, ética, jurídica, econômica e ambiental, em contexto de sobrevivência humana. Um conceito reducionista, focado no antropocentrismo, no econômico ou somente no ambiental, é um equívoco de comprovada insuficiência. Por isso, na proposta, a "[...] sustentabilidade é princípio-síntese que determina a proteção do direito ao futuro.”, como sintetiza Freitas (2012, p. 73). Para o autor, a sustentabilidade não é “[...] mera norma vaga, pois determina, numa perspectiva tópico-sistemática, a universalização concreta e eficaz do respeito às condições multidimensionais da vida de qualidade, com o pronunciado resguardo do direito ao futuro." (FREITAS, 2012, p. 76).

$\mathrm{Na}$ abordagem multidimensional, alcançar a meta da sustentabilidade condiz com o estudo que deu origem ao Relatório Brundtland e que apresenta propostas similares às premissas das teorias feministas de política decolonial ${ }^{1}$ e do bem viver latino-americanas. $\mathrm{Na}$ essência, propõe-se a melhoria da qualidade de vida em dimensões intersubjetivas, socioculturais, econômicas e socioambientais (GUDYNAS; ACOSTA, 2011). Embora sem

\footnotetext{
${ }^{1}$ Para as teorias políticas decoloniais, a colonização deve ser entendida como um acontecimento histórico que originou o colonialismo (QUIJANO, 2005), um processo persistente das formações sociais pela dominação de categorias de raça, classe e gênero (LUGONES, 2008). As epistemes decoloniais tornam visíveis os elementos de racionalização da sociedade e contribuem para afirmar um direito à existência digna, pela ampliação das capacidades e vida ativa, no contexto de bem viver.
} 
tradução exata, o neologismo do viver bem, de ter uma vida boa, corresponde à noção de um mínimo existencial, e se arquiteta numa perspectiva de sustentabilidade desmembrada da competição e do consumo desenfreado por considerá-los armadilha da colonização, uma subalternização eurocêntrica, e um meio de alienação e aprisionamento (ACOSTA, 2016).

O bem viver ${ }^{2}$, prática secular vivenciada pelas populações andinas ${ }^{3}$, difunde-se e torna-se conhecido como proposta de repensar o desenvolvimento pela matriz da autossustentabilidade em espaço e tempo comuns. $\mathrm{O}$ projeto tem firme propósito de fortalecer e superar as dicotomias das desigualdades, e das intersecções de raça, classe e gênero, e reduzir as privações que derivam do prepotente modelo capitalista e neoliberal. A proposta também traduz um desestímulo ao excesso de consumo, descentraliza o lucro e a renda, com a firme pretensão de valorizar os diferentes potenciais culturais, éticos e socioambientais.

Insta destacar que os indicadores, como o Índice de Necessidades Básicas (In)Satisfeitas, Índices de Vulnerabilidade, Índice do Desenvolvimento Humano e outros, possuem limitação para se aferir o bem viver, o que permite questionar se é próprio de seu significado sua dimensão subjetiva e, por assim ser, a ciência, de base racional, ainda tem dificuldade de dialogar com esses outros elementos sobre o tema. Dessa forma, surge a necessidade de se incorporar a visão transdisciplinar para melhor compreender tal fenômeno

Com matriz filosófica e ética, o bem viver fundamenta-se na teoria da libertação de Dussel (1977). O filósofo identifica, com base na realidade do continente latino-americano, a necessidade de emancipação ontológica ao considerar que o mundo deve ser um local de moradia digna para todos. O seu fundamento teórico é o de estimular e valorizar as potencialidades das diferentes manifestações culturais como tributo às diferenças, incentivar as proximidades, enaltecer a solidariedade e alteridade na concepção de ter uma vida boa no lugar em que se vive, desfrutando equilibradamente dos recursos naturais de cada região. Ao ignorar essa realidade ontológica, foca-se no modelo importado e gera-se um mau desenvolvimento (SACHS, 1993).

\footnotetext{
${ }^{2} \mathrm{O}$ conceito surgiu há mais de uma década (TEIJLINGEN; HOGENBOOM, 2017) e tem sido referido como: filosofia de vida (ACOSTA, 2010), cosmologia (WALSH, 2010), atitude de vida (CORTEZ, 2011), ontologia (THOMSON, 2011), modelo de desenvolvimento (RADCLIFFE, 2012) e alternativa ao desenvolvimento (GUDYNAS, 2011).

${ }^{3} \mathrm{O}$ bem viver se tornou visível com o reconhecimento nas Constituições da Bolívia e do Equador. Embora seja um conceito em construção, não se limita ao mundo indígena, propõe adotar princípios para superar a pobreza, conquistar a igualdade, valorizar a biodiversidade em relação harmônica dos seres humanos com a natureza (GUDYNAS; ACOSTA, 2008).
} 
Nesse contexto, podem-se apontar três correntes do bem viver: (1) a indigenista e pachamamista, (2) a socialista e estadista e (3) a pós-desenvolvimentista e ecologista.

A primeira e originária seria a corrente indigenista e pachamamista, caracterizada pela relevância que se dá a autodeterminação dos povos indígenas na construção do Bem Viver, assim como aos elementos mágicoespirituais (la Pachamama). [...] Estaria vinculada com o pensamento indígena pré-moderno. [...] A segunda seria a corrente socialista e estadista, caracterizada pela relevância que dá a gestão política-estatal do Bem Viver, assim como aos elementos relativos à equidade social [...] e a terceira seria a corrente post-desenvolvimentista e ecologista, caracterizada por relevância que se dá a construção participativa do Bem Viver, com a inclusão de aportes indigenistas, socialistas, feministas, teológicos e, sobretudo, ecologistas. Falam do Bem viver como uma alternativa ao desenvolvimento, como uma utopia em construção [...] (HIDALGO-CAPITÁN, 2012, p. 16).

Afirma Acosta (2016) que a defesa do bem viver é “[...] uma alternativa ao desenvolvimento, uma proposta civilizatória que reconfigura um horizonte de superação do capitalismo.” na América Latina. Essa reconfiguração “[...] constitui uma ruptura civilizatória necessária em tempos distópicos, e na urgência de se constituir sociedades solidárias e sustentáveis revaloriza as diversidades culturais e os modos de vida suprimidos pela homogeneização imposta[...]" conclui o autor (ACOSTA, 2016, p. 67). Nessa proposta do bem viver, o modelo Norte/Sul capitalista, colonizador e dominante (QUIJANO, 1992) é linear e desmedidamente antropocêntrico (GUDYNAS; ACOSTA, 2011), portanto se equivoca, inverte o foco, aloca o econômico no centro e o humano na periferia, gerando uma inversão que despreza riquezas e potenciais culturais e ambientais e ao mesmo tempo, produz miséria, exclusão, marginalização e indiferença.

A proposta de sustentabilidade latino-americana do bem viver denuncia a alienação e a opressão por entender que se constituem em vetores de privações e mazelas sociais. Nessa dinâmica, de subalternização e vulnerabilização de diversos grupos sociais encontram-se as mulheres. Com assente no ideário do colonialismo, os marcadores sociais de raça e gênero precisam estar dentre os olhares de observação quando se analisa o bem viver e o ecodesenvolvimento. Essa perspectiva semântica harmoniza-se com a proposta de Sachs $(2000)^{4}$, ao alertar a imposição eurocêntrica do capitalismo neoliberal por ser inadequada e por não considerar a inter-relação entre as dimensões econômica, social, cultural, política,

\footnotetext{
${ }^{4}$ Para Sachs (1993), o desenvolvimento deve ter relação com o crescimento econômico, aumento igualitário do bem-estar social e preservação ambiental. Esses fatores não devem ser considerados em modelo único, eis que no próprio país há desigualdade como as encontradas na divisão dicotômica entre o Norte e o Sul.
} 
ambiental e tecnológica, propõe o ecodesenvolvimento. Com os mesmos propósitos, bem viver e ecodesenvolvimento são considerados modelos de resistência, negam o mito do progresso a qualquer custo e almejam suplantar a relação impositiva que subalterniza e é predatória com a natureza e com as relações de gênero e raciais.

Os pontos fundantes da proposta do bem viver (QUIJANO, 1992; ACOSTA, 2016) e do ecodesenvolvimento (SACHS, 1993) sugerem resgatar o papel social do Estado e ampliar a participação política representativa e intercultural. As teorias realçam a importância de considerar os benefícios que o progresso e o desenvolvimento trouxeram e repensam meios de fortalecer uma concepção social, cultural, ambiental, política e jurídica mais igualitária e integrada, permitindo a participação popular em termos de desenvolvimento, como a sustentabilidade. Para alcançar os propósitos, indicam a necessidade de ampliar e qualificar as novas formas de fazer, de produzir por maneiras renováveis, conscientes, solidárias, em que o lucro não seja o objetivo central. Uma ideia de solidariedade e descomercialização dos serviços sociais, alcançada por políticas públicas que fortaleçam a concepção de um estado plurinacional com participação popular e acesso às instituições de modo igualitário.

Por ser um marco de oposição, o bem viver latino-americano valoriza o estado plurinacional, a interculturalidade, o pluralismo jurídico e os direitos da natureza como alternativas em harmonia, viáveis e possíveis. Seu legado é aderir a um modelo de sustentabilidade fortalecido na ética que centraliza o ser humano, descolado do gênero, não o dissocia pela etnia, cor da pele, classe, na sua intrínseca relação com a natureza, de forma a priorizar níveis satisfatórios de reconhecimento e promoção pelo viés intercultural das diferenças.

\section{Convergências epistêmicas ao bem viver: reflexões pontuais}

Os conceitos desenvolvimento e liberdade possuem semânticas variadas. Cada qual, assentado em sua episteme, traz consigo uma razão de existir. Nesse diálogo, Acosta (2016) indica que o discurso sobre desenvolvimento consolidou uma dominação dicotômica entre: desenvolvimento-subdesenvolvimento, pobre-rico, avançado-atrasado, civilizado-selvagem, centro-periferia e outros. Desse modo, países considerados empobrecidos e subalternizados passaram a utilizar indicadores, instrumentos e políticas públicas para apagar uma realidade imposta do estereótipo de "atrasado" para chegar ao desejado "desenvolvimento". 
Costumeiramente esses países negam sua historicidade e espelham-se em realidades de desenvolvimento utilizadas pelo colonizador.

Em consonância, o bem viver denuncia que a acumulação não é sinônimo de riqueza e que a fartura pode ser conquistada com o equilíbrio entre as necessidades fundamentais e os recursos disponíveis para satisfazê-las em uma relação geográfica e temporal. Esse argumento condiz com a ampliação das dimensões da sustentabilidade para promover melhoria em perspectiva solidária, intercultural e cooperativa. Logo, os referenciais teóricos, nas suas particularidades, aludem ao bem-estar e ao desenvolvimento a ser alcançado pela ampliação das capacidades humanas (SEN, 2010) de articular, como pressuposto da liberdade e da responsabilidade, em dimensões socioambientais, a construção de projetos de vida dignos.

A sustentabilidade concentrada no econômico, em crescimento do produto interno bruto, rendas, industrialização, consumo, avanço tecnológico e modernização social é um equívoco porque minimiza a relevância da promoção da dignidade em diversos sentidos. $\mathrm{Ou}$ seja, por meio das conexões teóricas, a ampliação das capacidades em bem viver permite participar em condição de equidade ou igualdade, com vistas às diferenças culturais e multiétnicas e da interculturalidade.

A socióloga Catherine Walsh (2009) aponta que a definição de bem viver é estabelecida por cada cultura. É preciso verificar as multiplicidades de cada grupo social e desse modo compreender que a interculturalidade é requisito para a prática do bem viver, mesmo porque não há como descolar individualidade de coletividade, isso é, ambas fazem parte de uma mesma dinâmica. Nesse sentido, "É a interculturalidade como processo e projeto social, político, ético e intelectual, que assume a decolonialidade como estratégia, ação e meta." (WALSH, 2005, p. 25). Assim, pode-se compreender o aspecto pedagógico do decolonial das práticas da decolonialidade como fazeres que orientam deslocamentos, inversões e rupturas herdadas pela consolidação das relações de dependência colonial e colonizadoras.

A interculturalidade é central na (re)construção de um pensamento crítico de/desde outro modo, precisamente por três razões principais: primeiro, porque está concebida e pensada desde a experiência vivida pela colonialidade, quer dizer, desde o movimento indígena; segundo, porque reflete um pensamento não baseado nos legados eurocêntricos ou da modernidade; e terceiro, porque tem sua origem no sul, dando assim uma volta a geopolítica dominante do conhecimento que tem seu centro no norte global. (WALSH, 2005, p. 25). 
Ao afirmar que viver apenas para subsistir não faz sentido, Arendt $(2020)^{5}$ critica a organização social baseada no excesso de trabalho como mecanismo distribuidor de renda e na ideia do alto consumo. Deixa um alerta: a servidão do trabalho, justificada pelas necessidades, é forma de dominação e aprisionamento, não permite conhecer e desenvolver outras atividades mais significativas. Essa ausência de liberdade, provocada pelas desigualdades, foco no trabalho e produção, impede participar ativamente nos espaços públicos, ampliando as invisibilidades e desigualdades.

As convergências epistêmicas aludem a um bem viver em harmonia, com interação social, cultural, ambiental, econômica e política. Se transformadas em ações alinhadas com o espaço e o tempo, podem impulsionar as mudanças almejadas e permitir uma ampliação das capacidades, um viver bem, uma vida ativa, e o bem-estar pelo viés do reconhecimento intercultural. A integração razoável do desenvolvimento sustentabilidade, da vida ativa como condição humana e do bem viver apresentam argumentos consistentes que permitem repensar a sustentabilidade social em igualdade de gênero pelo feminismo decolonial.

\section{Gênero e política da sustentabilidade}

Enfrentar a desigualdade de gênero é a proposta do projeto político da Agenda 2030, lançada em 2015, pela Organização das Nações Unidas, a qual incluiu, entre seus 17 Objetivos de Desenvolvimento Sustentável, o ODS 5, que propõe alcançar a igualdade de gênero e empoderar todas as mulheres (ONU, 2015). A meta inspirou-se no conteúdo da Plataforma de Pequim, da Quarta Conferência Internacional sobre a Mulher, em 1995 e, de forma mais tímida, baseou-se no relatório do Banco Mundial.

A inclusão na plataforma universal promete compreender as dimensões econômicas, sociais, políticas e ambientais. É considerada um avanço à luta pela igualdade de gênero não apenas em condições de pobreza, todavia de restrições em diversos países, independente do grau de desenvolvimento. Mas é duramente criticada pela polarização entre modelos capitalistas e socialistas de desenvolvimento sem apresentar propostas reais aptas a desnaturalizar os papéis do feminino e do masculino no combate à estrutura patriarcal (SCOTT; QUADROS, 2018). Contudo, a agenda política de estrutura liberal é importante instrumento

\footnotetext{
${ }^{5}$ Embora a filósofa política seja alemã, suas contribuições foram referidas no texto por coadunarem-se com a concepção de sustentabilidade social em bem viver.
} 
que registra os graves obstáculos à igualdade de gênero e a ineficiência das ações para acabar com a discriminação contra o feminino, impedindo avançar nas metas que visam pôr fim à pobreza, proteger o planeta como indica o Relatório Transformando Promessas em Ação: Igualdade de Gênero na Agenda 2030 para o desenvolvimento sustentável (ONU MUJERES, $2018)^{6}$.

O Relatório e o Informe El Progreso de las Mujeres em el Mundo 2019-2020: Familias em um mundo cambiante (ONU MUJERES, 2019) mostram que o tema é prioritário para atingir os demais objetivos, é uma abordagem integrada em direitos e políticas públicas, construído a partir de uma séria agenda política ${ }^{7}$ para sua implementação. No período de sua elaboração, a Comissão Econômica para a América Latina e Caribe - CEPAL emitiu um relatório intitulado: A autonomia das mulheres na mudança de cenários econômicos que reitera a desigualdade de gênero e a ausência de autonomia das mulheres como um sério obstáculo ao desenvolvimento sustentável. O estudo foi desenvolvido pela linearidade liberal e destaca a necessidade de reunir esforços na elaboração de estratégias de igualdade que reconheçam a contribuição das mulheres à economia na América Latina e no Caribe (CEPAL, 2019).

Nos marcos internacionais, o tema remonta, de forma mais específica, à Convenção sobre a Eliminação de Todas as Formas de Discriminação contra a Mulher, adotada pela Assembleia Geral da Organização das Nações Unidas, em 1979, a qual foi ratificada pelo Brasil. Desde a época, elaboraram-se muitas convenções internacionais que, de forma direta ou não, propõem garantir os direitos humanos às mulheres de forma isonômica à dos homens. No Brasil, não é diferente, a igualdade de gênero é direito fundamental formal e material, conta com suporte jurídico no artigo $5^{\circ}$, inciso I, da Constituição Federal, e é um desdobramento do princípio da igualdade, cujo fundamento está na prevalência da dignidade da pessoa humana,

\footnotetext{
${ }^{6} \mathrm{O}$ Relatório mostra que as desigualdades de gênero estão presentes em todos os países como um problema generalizado que exclui as mulheres do progresso pela dificuldade de acessar a educação, saúde, água potável, renda em múltiplas variáveis e dimensões do desenvolvimento sustentável. Os dados indicam que a desigualdade é mundial. Há 122 mulheres com idade entre 25 e 34 anos que vivem em pobreza extrema, enquanto, entre os homens desse mesmo grupo etário, há 100. Na América Latina e Caribe, existem 132 mulheres que vivem nessas condições enquanto, entre os homens desse mesmo grupo etário, há 100 . As mulheres divorciadas maiores de 15 anos têm o dobro de chances de viver em extrema pobreza que os homens na mesma faixa etária. O percentual de mulheres pobres divorciadas na América Latina e no Caribe atinge 15,8\%. Em nível mundial, a carga de trabalho doméstico e de cuidado não remunerado, realizado por mulheres, é 2,6 vezes maior do que assumem os homens. As mulheres são proprietárias de apenas $13 \%$ das propriedades agrícolas no mundo. Em relação à participação política, as mulheres têm ocupado apenas $23,7 \%$ dos espaços parlamentares no mundo. Das 100.000 mulheres mortas, 2,3\% tiveram como causa o feminicídio (ONU MUJERES, 2018).

${ }^{7}$ Dentre as recomendações do Relatório, destacam-se que a agenda política deve: a) Garantir o serviço público acessível e de qualidade para apoiar as famílias e promover a igualdade de gênero; b) Prever formas de garantir tempo, dinheiro e serviço dentro e fora da família; c) Garantir recursos necessários para políticas orientadas às famílias; d) Prevenir e responder pela violência familiar contra as mulheres; e) Sancionar e implementar leis voltadas às famílias na diversidade, igualdade e não discriminação (ONU MUJERES, 2019).
} 
princípio de matriz constitucional, sendo que sua inobservância implica prática discriminatória, veda o exercício dos direitos de cidadania de forma paritária e perpetua relações de poder entre gêneros ${ }^{8}$.

Ocorre que atingir as pretensões expressas nos marcos regulatórios nacionais e internacionais exige esforço político para aprofundar o tema e superar as dimensões ideológicas: a naturalização das competências e habilidades; e consequentemente a remuneração iníqua decorrente da desvalorização associada ao feminismo; e o acesso a desigual tempo livre, diante da influência da aceitação de responsabilidades como femininas, subjacentes à incumbência precípua das mulheres pelas tarefas domésticas, incluindo o dever de cuidado, que constitui o cerne da alocação desigual de responsabilidades (BIROLI, 2016). Além da igualdade formal de matriz liberal, as demandas dos movimentos feministas de políticas decoloniais são pelo reconhecimento de direitos, de modo a suprimir empecilhos legais, econômicos e sociais, que obstaculizam seu acesso às representações políticas, educação e emprego pela desconstrução da categoria e do lugar da mulher.

Para que seja possível a mulher alcançar com eficácia a dignidade em marcos nacionais e internacionais, garantir um bem-estar em uma vida ativa, é necessário que tenha assegurado o seu reconhecimento como pessoa não generificada e racializada, para que possa eleger prioridades como ser humano, como sujeito detentor de autonomia decisória na sua vida e nas relações intersubjetivas na família e na sociedade. Essas reivindicações, derivadas dos dados que foram levados à Agenda 2030 da sustentabilidade, permitem concluir que as mulheres exercem alta carga do trabalho não remunerado, têm acesso desigual a recursos econômicos e poder, são vítimas de violência e de subordinação. Porém, o reconhecimento nas agendas políticas não é suficiente para garantir a efetividade das normas e ações, quer seja pela ausência de sanções contundentes, superficialidade das políticas públicas e, principalmente, pela histórica naturalização estrutural que atribui ao gênero uma categoria binária e colonial.

\section{Igualdade de gênero e sustentabilidade social: reflexões decoloniais}

\footnotetext{
${ }^{8}$ A isonomia propõe dar eficácia ao propósito de construir, com fundamento no artigo $3^{\circ}$, IV, da Constituição Federal, uma sociedade livre, justa e solidária, bem como promover o bem-estar, sem preconceitos ou discriminações. Além da previsão expressa, a igualdade de gênero caracteriza-se como formal, o conteúdo abraça uma dimensão material e alberga a abertura do catálogo de direitos fundamentais, consagrada expressamente pelo artigo $5^{\circ}, \S 2^{\circ}$, da Constituição Federal.
} 
Alcançar a igualdade de gênero é condição necessária à sustentabilidade social e constitui-se como fundamento do bem viver. Para efetivá-la, torna-se essencial compreender que, na história da América Latina, a emancipação da mulher é considerada uma desobediência epistêmica, uma resistência à continuidade de uma lógica da hegemonia eurocêntrica, estruturada no processo de colonialização que reproduz a categoria binária do "humano" e do "não humano" (LUGONES, 2014).

A premissa da igualdade pressupõe romper com a hierarquia do poder colonizador que, pelas estruturas e subjetividades, continua colonizando o ser, o saber e a natureza. Essa proposta decolonial justifica-se pelas ilações das diferenças humanas, históricas, culturais e abismos econômicos entre o Norte e o Sul, na perspectiva de respeitar o ser e o viver em pluralidade. Para atingir a emancipação, supera-se o controle pelo gênero, que no recorte histórico é oriundo da separação eurocêntrica entre o colonizado e o colonizador, o humano e o não humano (WALSH, 2019; LUGONES, 2014), fomenta um frágil modelo da igualdade formal e de desenvolvimento que, ao valorizar a ideia monocultural, amplia as desigualdades, aprisiona e oprime o ser humano em matriz de gênero, raça e classe.

O projeto do bem viver propõe alcançar a sustentabilidade pela valorização das múltiplas diferenças que é contrária à lógica binária, amplamente criticada por Butler $(2017)^{9}$ e Lugones (2014). Considera que o modelo global amplia as fragilidades e as insuficiências porque se organiza em torno da produção do "outro" como inferior, padroniza e desconsidera as dimensões humanas, suas relações com a cultura, natureza, tempo e espaços geográficos. Opondo-se, o bem viver idealiza a superação dos estereótipos, das invisibilidades e exclusões, e permite pensar em um modelo de sustentabilidade social harmônico, comunitário e plural, que valoriza as manifestações humanas, interculturais e suas relações com a biodiversidade.

No modelo de origem andina, a igualdade de gênero, centrada na proposta binária global, soa estranha, no sentido de que o gênero é apenas um, o humano, sem partição (LUGONES, 2014). Por isso, o ideal político e normatizado nos documentos internacionais de um humano universal, alienado pelos signos da raça, sexo e classe, é o que se pretende apagar nas relações intersubjetivas, sociais e ambientais de um estado plurinacional e iminentemente participativo. Nessa articulação multimensional das pessoas em sua cultura e ambiente, o

\footnotetext{
${ }^{9}$ Parte da literatura decolonial critica a filósofa estadunidense Butler. As reflexões são trazidas ao texto para reafirmar que a categorização "mulher" perpassa por uma relação de poder que se expressa pela linguagem, marginalizando e subalternizando. A sugestão da filósofa na obra é a desconstrução da identidade de gênero para colocar em xeque os binarismos e atestar as suas fragilidades em um mundo diverso e plural. Nestes termos, as propostas de Butler, de certa forma, se aproximam dos propósitos do bem viver em perspectiva decolonial.
} 
propósito é o de reduzir os poderes e as interferências institucionais que, pelas subjetividades, produzem e reproduzem uma lógica eurocêntrica e patriarcal de hierarquias, do consumo exagerado, do excesso de trabalho, da ausência de participação política, e adoecem. A proposta, como dito, é de resistência e oposição ao legado colonizador que retroalimenta a dicotomia patriarcal do gênero e suas inter-relações que subalternizam e impede atingir a sustentabilidade social.

Ao reconhecer que os seres humanos formam parte de um contexto harmônico com a natureza e outros seres, cruza-se a linha do lugar da mulher, do público e do privado (OKIN, 2008) reduzindo as diferenças como meta da sustentabilidade social. A proposta de viver bem reconhece o alerta de Okin (2008) sobre os perigos da multiculturalidade, por usar do manto protetivo da cultura para manter a lógica de submissão e comportamentos na esfera doméstica que afetam as mulheres. Porém, enfatiza que a mudança na simbologia patriarcal da mulher deve acontecer no seio familiar por ser ambiente em que as estruturas de poder da raça, sexo e gênero se retroalimentam, produzem-se e se reproduzem. O escopo é de correção das discrepâncias que podem subliminar disparates com o objetivo de reservar ao homem o trânsito pela esfera pública, enquanto a mulher, embora tenha conquistado certo espaço, permanece fragilizada em termos sociais e políticos, circunscrita ao espaço privado, com o papel idealizado, invisível e não remunerado de cuidar do lar e da família ${ }^{10}$.

O bem viver, conectado ao feminismo de política decolonial, ${ }^{11}$ respeita as relações interculturais, mas não adere aos preceitos de um multiculturalismo de sobreposição servil, que pode ser usado como sinônimo de tradição, conforme alerta Okin (2008). A alternativa não permite deslocar a mulher ao delimitado espaço doméstico e de divisão sexual de tarefas pelas imposições históricas, culturais ou políticas, fato que gera o seu afastamento de participação política e social, naturalizando um produto historicamente forjado ${ }^{12}$. Assim, não assimila o

\footnotetext{
${ }^{10}$ A produção do gênero não deve ser isolada de outras variáveis, como padrões de hierarquias gerados pelo acesso ao trabalho, maior renda, estudo, raça, entre outras, afirma Biroli (2016).

11 Os feminismos descoloniais estudam formas de romper com o processo de colonização pelas estratégias complexas de superação das complexidades do racismo, sexismo e etnicismo que impregnam as relações de dominação (VÈRGES, 2020).

12 As mulheres continuam trabalhando muito mais horas do que os homens nos afazeres domésticos e no desempenho do cuidado, além de, a despeito da maior escolarização, seguirem recebendo salários menores e ocuparem menos cargos de poder. Para exemplificar, em 2016 e 2017, mulheres brasileiras, em geral, trabalharam cerca 18,1 horas por semana em cuidados e/ou afazeres domésticos, enquanto os homens trabalharam 10,5 horas (o que significa que as mulheres dedicavam 73\% mais horas do que os homens); a média salarial dos homens foi de aproximadamente $\mathrm{R} \$ 2.306,00$, enquanto a das mulheres correspondeu a $\mathrm{R} \$ 1.764,00$ (cerca de $3 / 4$ do montante recebido pelos homens); mulheres ocuparam perto de 39,1\% dos cargos de gerência nas empresas públicas e privadas, ao passo que os homens 60,9\%; e apenas 10,5\% dos deputados na Câmara eram mulheres (IBGE, 2018). Além disso, cerca de $24,2 \%$ das mulheres brasileiras, entre 15 a 29 anos de idade, que não estavam estudando, justificaram a impossibilidade de estudar por precisarem cuidar dos afazeres domésticos ou de criança,
} 
discurso de raízes eurocêntricas que conserva as estruturas de poder e subalterniza as mulheres em categoria (BUTLER, 2017) e no padrão universal de igualdade, revelando um importante obstáculo à dimensão social da sustentabilidade em igualdade de gênero.

O aparente descuido epistêmico da linearidade no tratamento isonômico do gênero, adotado pelas agendas políticas da sustentabilidade, reconhecem como um direito humano universal e ocultam a mesma ideologia eurocêntrica da desigualdade. Como consequência, as teorias do desenvolvimento não têm mostrado eficiência para enfrentar as relações subjetivas de poder que se inter-relacionam na família e no laço social, conservando a dualidade do lugar da mulher e do homem no modelo colonizador binário do "humano" e do "não humano", do homem e da mulher. Nesses lugares marcados, que entrelaçam o simbólico e o real, pelo padrão que se retroalimenta, reproduzem-se as diferenças que limitam as possibilidades de atuação da mulher em termos mais amplos, sociais, econômicos e políticos (BIROLI, 2018) limitando a conquista do equilíbrio em igualdade e sustentabilidade.

Os dados estatísticos revelam as diferenças de remuneração ${ }^{13}$, a divisão sexual do trabalho ${ }^{14}$ e de cuidado, ou são usados como estratégias para manter invisíveis as mulheres racializadas e que, pela interseccionalidades das relações, ampliam as vulnerabilidades, a tolerância com a violência, a ideologia da feminização da maternagem, os limites do controle autônomo da capacidade reprodutiva, consequentemente, geram impactos importantes e fragilizam uma equilibrada concepção social do desenvolvimento. A demarcação da raça e do gênero tem limitado o espaço de atuação da mulher e mascarado a marginalização nas múltiplas dimensões da sustentabilidade: a feminização da pobreza; a violência contra a mulher; a precária participação feminina na política e decisória; a falta de isonomia de oportunidades; o pouco acesso aos recursos financeiros.

Todas as desigualdades visíveis ou invisíveis inferiorizam a mulher e demarcam a naturalização das funções e dos espaços e são um obstáculo capaz de impedi-las de assegurar a sua condição humana na perspectiva arendtiana de uma vida ativa, constituindo-se em restrição

\footnotetext{
adolescente, idosos ou pessoa com deficiência. Esse motivo foi citado por somente $0,7 \%$ dos homens, correspondendo à menor porcentagem das justificativas obtidas do público masculino (IBGE, 2019).

${ }^{13} \mathrm{Na}$ PNAD Contínua - Pesquisa Nacional por Amostra de Domicílios Contínua, realizada pelo IBGE - Instituto Brasileiro de Geografia e Estatística, resta comprovado que as mulheres brasileiras, em todas as ocupações, ganham menos que os homens. Se os dados forem comparados, entre 2012 e 2018, a pesquisa mostra uma queda na desigualdade, porém, em média, 20,5\% das mulheres ganham menos que os homens no país (IBGE, 2019).

${ }^{14} \mathrm{O}$ estudo do IBGE, com base na PNAD Contínua - Pesquisa Nacional por Amostra de Domicílios Contínua, de 2018, mostra que permanece a diferença da carga horária diária trabalhada entre homens e mulheres, embora venha, em termos oficiais, diminuindo (IBGE, 2019). A diferença de 6 horas de 2012 caiu para 4 horas e 48 minutos em 2018. A jornada não apresenta o fato de as mulheres trabalharem em outras atividades domésticas e por cuidados com membros da família (IBGE, 2019).
} 
à expansão das capacidades e liberdades. A superação das discriminações aparentes ou veladas tem propósito de descentralizar as hierarquizações e impedir a perpetuação limitativa do pleno exercício de direitos humanos e fundamentais em perspectiva intercultural, óbices à consolidação da cidadania e do desenvolvimento sustentável.

No cenário latino-americano do bem viver, como explica Lugones (2008), a igualdade de gênero, recepcionada pela episteme decolonial, é considerada uma resistência da manutenção da política da colonialidade do poder que se fortalece por meios (in)visíveis e é imposta a uma organização social do sexo, a qual contribui para reduzir o gênero ao ambiente privado. Nessa concepção, a isonomia pode parecer frágil pela contravenção, perigosa à lente política neoliberal, de modo que resta o alerta: sem o devido cuidado com as armadilhas universalistas, a mulher poderá ser conduzida a uma dimensão ampliada de subordinação pela invisibilidade, contrária à luta pela superação.

A proposta também é de uma cidadania ativa como condição humana (ARENDT, 2020) que deve se dar no contexto da representatividade e do poder. Bourdieu (2005) a reconhece como sendo a chave para a mudança da realidade social. Embora as mulheres sejam a maioria da população brasileira ${ }^{15}$, elas ainda possuem inexpressiva participação nos centros decisórios. As falhas na construção de uma isonomia em termos econômico, participativo e decisório constituem-se em fragilidades a serem enfrentadas por políticas públicas de educação inclusiva e conscientização, que visam a desmistificar as estruturas eurocêntricas de poder, ampliar os debates e reflexões, qualificando a participação e a representatividade política, bem como fortalecer as instituições em termos plurais.

O feminismo de política decolonial latino-americano em sintonia com o bem viver propõe o debate, reivindica a inclusão e a igualdade material, não apenas formal, e faz denúncia das diversas e não padronizadas necessidades humanas. As estratégias sinalizam efetivar uma isonomia na autonomia intercultural, participativa em termos sociais e financeiros, novas formas de inserção e deliberação nas instituições políticas, e apresentam críticas à integração da mulher como número de equidade ao sistema econômico e aos mercados especulativos neoliberais (BIROLI, 2018), com o propósito de construir um novo projeto político mais solidário e participativo e um redesenho das instituições plurinacionais em contínuo aperfeiçoamento.

\footnotetext{
${ }^{15}$ Segundo dados da Pesquisa Nacional por Amostras de Domicílios Contínua (IBGE, 2018), as mulheres são
} $51,8 \%$ da população brasileira. 
O acesso das mulheres ao espaço público como renúncia à herança patriarcal do poder pode ser conquistado pela reivindicação dos movimentos sociais ${ }^{16}$ se trabalhado seriamente em políticas públicas descoloniais ${ }^{17}$. O propósito é assegurar, com base na igualdade intercultural, alcançada pelo reconhecimento das diferenças, a participação feminina nas instituições e na política, uma ruptura das relações de poder eurocêntricas, de modo a consolidar um modelo de sustentabilidade pautado nas ideologias do feminismo decolonial e do bem viver.

\section{Conclusão}

A reflexão foi movida pelo objetivo de investigar o bem viver como paradigma da sustentabilidade social em igualdade de gênero pela episteme do feminismo decolonial. Importante destacar que a sustentabilidade, em termos multidimensionais, precisa enfrentar as graves deficiências no atual contexto das políticas econômicas e sociais assentadas na desigualdade, no consumo exacerbado e na fluidez da sociedade pós-moderna. As diretrizes decoloniais do projeto latino-americano do bem viver propõem superar os desafios do desenvolvimento pela valorização das inter-relações identitárias e socioambientais. Na sua essência, está o propósito de fortalecer a condição humana e de agente, a ser conquistada pelo estreitamento das conexões entre as pessoas nas culturas, etnias, geografias, ideologias, e em suas relações com a natureza, afastando-se de marcadores de raça e gênero.

A alternativa do bem viver projeta alcançar o equilíbrio entre social, ecológico, econômico, espacial, digital e cultural como meio essencial para uma política de enfrentamento das invisibilidades geradas pelas mazelas sociais e econômicas que agravam as privações decorrentes das assimetrias estruturais e suas interseccionalidades que delimitam o gênero em categoria binária. Todavia, como proposta de resistência e (re)existir, o bem viver propõe lutar contra as opressões de uma geopolítica eurocentrista e sustenta a adoção de uma ideologia coletiva, harmônica, democrática e participativa, com redução do consumo, valorização da

\footnotetext{
${ }^{16}$ Os movimentos sociais, atores de fundamental importância para a sociedade civil, como meio de manifestação e reivindicação de causas sociais e políticas, são também fenômenos históricos que pretendem transformar e introduzir mudanças estruturais nas sociedades. O movimento social feminista no Brasil teve várias etapas, para este estudo, destaca-se a atuação no campo da política de modo a ampliar a participação das mulheres nas esferas representativas públicas.

${ }^{17} \mathrm{O}$ movimento feminista, em especial, o decolonial, é um importante ator que estimula mudanças socioculturais com propósito de alcançar a igualdade em termos amplos, na interseccionalidade das diferenças, e não somente na aquisição de renda, na remuneração pelo trabalho, do cuidado e outros que são invisíveis, pela participação isonômica nas instituições políticas, consolidando preceitos constitucionais de sociedade solidária e participativa.
} 
cultura e equilíbrio com o meio ambiente. Nesse sentido, mantém o firme propósito de promover uma melhoria das condições de vida e do bem-estar não apenas no presente, mas também para as futuras gerações.

É um paradigma para orientar as políticas e ações dos Estados nacionais, que devem regular as relações sociais com o fim de diminuir as desigualdades na sociedade e melhorar as condições de vida dos economicamente vulneráveis. Nesses termos, o diálogo em torno do bem viver sugere repensar a própria definição de desenvolvimento, relativizando-o, a partir do entendimento de interculturalidade. Na perspectiva decolonial, propõe-se uma sustentabilidade social em articulação, com correspondência às estruturas de poder para desconstruir a desumanização promovida pela manutenção generificada das normativas isoladas do contexto histórico e social.

Em atenção às ações das agendas políticas e às clássicas teorias do desenvolvimento, a desigualdade de gênero é indicada como limite à sustentabilidade social, e as estratégias apresentadas indicam o enfrentamento integrado à política neoliberal associada à estrutura eurocêntrica que reproduz o poder patriarcal, universaliza e encarcera a mulher na categoria do determinismo biológico. Pela incoerência comprovada nos dados e estatísticas, a igualdade em termos interculturais deve ser conquistada pela paulatina supressão da lógica binária da diferença que molda, produz e reproduz as estruturas de poder, ser e saber, e naturaliza a subalternização da mulher no pertencimento ao gênero, raça e classe social, demarcando as dimensões das injustiças.

Essa perversa lógica política, social e econômica deve ser enfrentada por projetos políticos alternativos, como o do bem viver, que incluem o paradigma da igualdade material, em respeito as diferenças, de gênero do feminismo de política decolonial. O pensamento emancipatório é razoável e sintoniza-se com os preceitos da sustentabilidade multidimensional e da vida ativa para um desenvolvimento equilibrado. Assim, as premissas decoloniais podem estruturar novas e suficientes políticas públicas comprometidas a superar essa fragilidade da condição humana que se reflete em limitação das liberdades e capacidades pela definição padronizada de funções e lugares de homens e mulheres, responsabilidades desiguais, submissões, e demais fatores de distinção, privando o acesso coletivo ao bem-estar como óbice à justiça, à cidadania ativa, aos direitos humanos e fundamentais e à sustentabilidade social.

\section{Referências}


ARENDT, Hannah. A condição Humana. Rio de Janeiro: Forense, 2020.

ACOSTA, Alberto. O Bem Viver: uma oportunidade para imaginar outros mundos. Rio de Janeiro: Elefante, 2016.

ACOSTA, Alberto. El Buen Vivir en el camino del post-desarrollo: una lectura desde la Constitución de Montecristi. Friedrich Ebert Stiftung. In: Policy Paper, 9 oct. de 2010.

BIROLI, Flávia. Divisão sexual do trabalho e democracia. Revista das Ciências Sociais, Rio de Janeiro, v. 59, n. 3, p. 719-754, 2016.

BIROLI, Flávia. Gênero e desigualdades: limites da democracia no Brasil. São Paulo: Boitempo, 2018.

BOURDIEU, Pierre. O poder simbólico. Rio de Janeiro: Nova fronteira, 2005.

BUTLER, Judith. Problemas de gênero. Feminismo e subversão da identidade. Rio de Janeiro: Civilização brasileira, 2017.

COMISIÓN ECONÓMICA PARA AMÉRCIA LATINA Y EL CARIBE - CEPAL. La autonomía de las mujeres en escenarios económicos cambiantes. Santiago: ONU, 2019.

CORTEZ, David. La construcción social del "Buen Vivir" (Sumak Kawsay) en Ecuador. In: Aportes Andinos, 28, p.1-23, 2011.

DUSSEL, Henrique Domingo. A filosofia da libertação. São Paulo: Loyola, 1977.

FREITAS, Juarez. Sustentabilidade. Direito ao Futuro. Belo Horizonte: Fórum, 2012.

GUDYNAS, Eduardo; ACOSTA, Alberto. EI buen viver mas allás del desarrollo. Quehacer. Lima: Desco, 2008.

GUDYNAS, Eduardo. ACOSTA Alberto. La renovación de la crítica al desarrollo y el buen vivir como alternativa. Utopía y Praxis Latinoamericana. Revista Internacional de Filosofía Iberoamericana y Teoría Social, n. 53, p. 71-83, abr/jun. 2011.

GUDYNAS, Eduardo. Buen Vivir: Today's tomorrow. In: Development, 54(4), p.441-447, 2011.

HIDALGO-CAPITÁN, A. L. El buen vivir ecuatoriano en el con-texto de la economía política del desarrollo. En: Dominguez, R.; Tezanos, S. (Eds.). In: Actas del I Congreso Internacional de Estudios del Desarrollo. Santander: Universidad de Can-tabria: 2012. Disponível em: http://congresoreedes.unican.es/actas/PDFs/202.pdf. Acesso em: 11 nov. 2020.

INTITUTO BRASILEIRO DE GEOGRAFIA E ESTATÍSTICA- IBGE. Pesquisa Nacional por Amostra de Domicílios Contínua. Divulgação Especial Mulheres no Mercado de Trabalho. Rio de Janeiro: IBGE, 2019.

INTITUTO BRASILEIRO DE GEOGRAFIA E ESTATÍSTICA - IBGE. Pesquisa Nacional por Amostra de Domicílios Contínua. Estatística de Gênero. Rio de Janeiro: IBGE, 2018. 
QUIJANO, Aníbal. Colonialidad do poder, eurocentrismo e América Latina. In: LANDER, Edgardo (org.). A colonialidade do saber: eurocentrismo e clínicas sociais. Perspectivas latino-americanas. Buenos Aires: Clacso, 2005. p. 117-142.

QUIJANO, Aníbal. Colonialidad y modernidad/racionalidade. Perú Indígena, v. 12, n. 29, 1992, p.11-20.

LUGONES, María. Colonialid y género. In: Tábula Rasa. Universidad Colegio Mayor de Cundinamarca. Bogotá, n. 9, p. 73-101, jul./dic. 2008.

LUGONES, María. Rumo a um feminismo decolonial. Revista de estudos feministas, v. 22, n. 3, p. 929-934, 2014.

ORGANIZAÇÃO DAS NAÇÕES UNIDAS - ONU. Meio Ambiente. Relatório Brundtland. 1987. Disponível em: https://sustainabledevelopment.un.org/content/documents/5987ourcommon-future.pdf . Acesso em: 20 set. 2020.

ORGANIZAÇÃO DAS NAÇÕES UNIDAS - ONU. AGENDA 2030: 17 Objetivos para transformar o mundo. 2015. Disponível em: https://nacoesunidas.org/pos2015/agenda2030/. Acesso em: 7 set. 2020.

ORGANIZAÇÃO DAS NAÇÕES UNIDAS MUJERES - ONU MUJERES. Hacer las promesas realidad. La igualdad de género em la agenda 2030 para el desarrollo sostenible. 2018. Disponível em: https://www.unwomen.org//media/headquarters/attachments/sections/library/publications/2018/sdg-report-fact-sheetlatin-america-and-the-caribbean-es.pdf?la=en\&vs=0. Acesso em: 28 jun. 2020.

ORGANIZAÇÃO DAS NAÇÕES UNIDAS MUJERES- ONU MUJERES. Familias em um mundo cambiante: El progresso de las mujeres en el mundo 2019-2020. Nova Iorque: ONU MUJERES, 2019.

OKIN, Susan Moller. Gênero, o público e o privado. Revista Estudos Femininos, v.16, n. 2, p. 305-332, 2018. Disponível em: https://doi.org/10.1590/S0104-026X2008000200002.

Acesso em: 24 jun. 2020.

RADCLIFFE, Sarah A. Desenvolvimento para uma era pós-neoliberal? Sumak kawsay, viver bem e os limites para a descolonização no Equador. Geoforum, 43(2), p. 240-249, 2012.

SACHS, Ignacy. Caminhos para o desenvolvimento sustentável. Rio de Janeiro: Garamond, 2000.

SACHS, Ignacy. Estratégias de transição para o século XXI: desenvolvimento e meio ambiente. São Paulo: Studio Nobel/ Fundap, 1993.

SCOTT, Russell Parry; QUADROS, Marion Quadros. Desenvolvimento, poder, gênero e feminismo.: Dossie desenvolvimento, poder, gênero e feminismo. Campinas: Caderno Pagu, n. 52, nov. 2018.

SEN, Amartya. O desenvolvimento como liberdade. Trad. Laura Teixeira Motta. Rev. Téc. Ricardo Doninelli Mendes. São Paulo: Companhia das Letras, 2010. 
TEIJLINGEN, Karolien Van; HOGENBOOM, Barbara. Debating alternative development at the mining frontier: buen vivir and the conflict around el Mirador Mine in Ecuador. In:

Journal of Developing Societies, 2017.

THOMSON, Bob P. Perspectivas indígenas, buen vivir, kawsay Sumaq e decrescimento. In: Desenvolvimento , 54(4), p. 448-454, 2011.

VÈRGES, Françoise. Um feminismo decolonial. Trad. Jamille Pinheiro Dias e Raquel Camargo. São Paulo: Ubu Editora, 2020.

WALSH, Catherine. Interculturalidade, estado, sociedad. Luchas (de)coloniales de nuestra epoca. Quito: Universidad Andina Simón Bolívar e Abya-Yala, 2010

WALSH, Catherine. Interculturalidade e decolialismo do poder um pensamento e posicionamento "outro" a partir da diferença colonial. Revista eletrônica da faculdade de direito da Universidade Federal de Pelotas (UFPel), Pelotas, v. 5, n.1, p. 6-39, jan./jul.2019.

WALSH, Catherine. (Re)pensamiento crítico y (De)colonialidad. In: Walsh, C. (Ed.). Pensamiento crítico y matriz (de)colonial.Reflexiones latinoamericanas. Quito: Universidad Andina Simón Bolívar Ediciones Abya-Yala, 2005.

Data de recebimento: 01.02.2021

Data de aprovação: 03.03.2021 